\section{Serum Adipokine Levels and their Relationship with Fatty Acids in Patients with Chronic Periodontitis}

\author{
Manuela Rubim Camara Sete, Ronaldo Lira Júnior, Ricardo Guimarães \\ Fischer, Carlos Marcelo da Silva Figueredo
}

Department of Integrated Clinical Procedures, School of Dentistry, UERJ - Rio de Janeiro State University, Rio de Janeiro, RJ, Brazil

Correspondence: Carlos Marcelo da Silva Figueredo, Boulevard 28 de Setembro, $157,2^{\circ}$ andar, 20551030 Rio de Janeiro, RJ, Brasil. Tel:+55-21-2868-8031. e-mail: cmfigueredo@hotmail.com

\begin{abstract}
Adipokines are present in inflammatory processes and may be directly related to periodontal disease. Moreover, their activities may be regulated by fatty acids. The goal of this study was to quantify the concentrations of the main adipokines, leptin, adiponectin and resistin, and the docosahexaenoic (DHA), docosapentaenoic (DPA), eicosapentaenoic (EPA) and arachidonic (AA) fatty acids, in patients with generalized chronic periodontitis. As a secondary objective, the ratios of these substances in the blood of these patients were evaluated. The study included 15 systemically healthy patients with generalized chronic periodontitis (test group) and 15 patients with gingivitis (control group). Medical and periodontal parameters and blood samples were collected. Serum concentrations of fatty acids were analyzed by gas chromatography and adipokines by multiplex bead immunoassay. There was no significant difference in adipokines between groups. However, there was a tendency for lower values of adiponectin in periodontitis patients. Regarding the fatty acids, they were significantly higher in the test group compared with controls. The res/DHA, res/AA, adipon/DHA, adipon/AA and adipon/DPA ratios were significantly lower in the test group. There was no significant correlation between adipokines and clinical parameters and between adipokines and fatty acids levels. It was concluded that generalized chronic periodontitis patients showed significantly higher levels of fatty acids in comparison to gingivitis; adiponectin revealed a trend to lower values in the periodontitis group, even after Ancova correction. The ratios suggest a minor proportion of adiponectin and resistin in relation to the fatty acids in patients with generalized chronic periodontitis.
\end{abstract}

Key Words: periodontitis, fatty acids, leptin, resistin, adiponectin.

\section{Introduction}

The term periodontal disease refers to inflammatory disorders induced by pathogenic microorganisms of the biofilm formed surrounding the teeth. Gingivitis, the mildest form of periodontal disease, is highly prevalent and readily reversible by effective oral hygiene. Inflammation extending deep into the tissues causing loss of connective tissue and alveolar bone is known as periodontitis. It results in the formation of pockets between the gingival tissue and tooth root, and may result in tooth loss (1).

Although bacteria are necessary for development of periodontal disease, it also requires a susceptible host. The host response is traditionally mediated by lymphocytes $T$ and $\mathrm{B}$, neutrophils and monocytes/macrophages. They are triggered to produce inflammatory mediators, including cytokines, chemokines, arachidonic acid metabolites and proteolytic enzymes, which collectively contribute to tissue degradation and bone resorption by activation of various degradation pathways (2).

These immune cells, their products (especially cytokines) and their complex interactions have led to studies focused on components of the immune-inflammatory response (3). Recently, it was demonstrated that adipokines derived from adipose tissue, are important in various physiological and pathological inflammatory responses (4). Adipose tissue is no longer considered an inert tissue that functions only as an energy carrier; it is recognized as an endocrine/paracrine organ, which is able to regulate various physiological processes. Over 50 adipokines secreted by adipose tissue have been described, including hormones, cytokines, chemokines and other proteins with specific biological functions. Leptin, adiponectin and resistin are the most studied adipokines $(5,6)$. Initially considered as markers of weight regulation and insulin resistance, it is becoming clear that these adipokines are involved in a variety of functions and conditions including cardiovascular disease, diabetes, and inflammatory diseases (5). Altered levels of adipokines have been observed in systemic inflammatory conditions such as inflammatory bowel disease and rheumatoid arthritis, but little is known about the potential association between adipokines and chronic periodontitis in systemically healthy individuals $(4,6,7)$.

Polyunsaturated fatty acids omega- 3 and -6 (PUFAs $n-3$ and n-6) also participate in chronic inflammation and may act as important inflammatory modulators. The reason for this effect is unknown, but an increased expression of cyclooxygenase (COX) and lipoxygenase (LOX) can affect the production of some eicosanoids, lipoxins, resolvins 
and other oxidized derivatives (8). The most important PUFAs are derivatives of $n-3$ : docosahexaenoic acid (DHA), eicosapentaenoic acid (EPA), and docosapentaenoic (DPA) acid, and of $n-6$ : arachidonic acid (AA).

Fatty acids may influence the expression of adipokines such as leptin, resistin and adiponectin directly by interaction with transcription factors, or indirectly by unknown mechanisms, possibly linked to oxidation, synthesis or storage of fatty acids. Since fatty acids are the major components of adipose tissue, is of paramount importance to clarify the biological effects of their different types in the expression of adipokines (9). Therefore, the aim of this study was to compare the concentrations of leptin, resistin and adiponectin and DHA, DPA, EPA and AA in the blood of patients with generalized chronic periodontitis and of patients with gingivitis. A secondary objective was to evaluate the proportion of these substances in the serum of these patients.

\section{Material and Methods}

Fifteen patients with generalized chronic periodontitis ( 3 men and 12 women, mean age: $45.7 \pm 9.4$ years) and 15 patients with gingivitis ( 3 men and 12 women, mean age $32.1 \pm 7.8$ years) participated in the study. All subjects were seeking for dental treatment at the Rio de Janeiro State University (UERJ), Rio de Janeiro, RJ, Brazil. The study protocol was approved by the Ethics Committee of the University Hospital Pedro Ernesto (UERJ, Rio de Janeiro, Brazil - 2714/2010). Patients had at least 20 natural teeth and were diagnosed according to American Academy of Periodontology criteria (10) .

Participants reported no present systemic disease and were not taking any medication that could affect periodontal conditions. They were non-smokers and neither used antibiotics for a minimum period of the last six months nor anti-inflammatory for the last three months. Participants did not have periodontal treatment in the last six months. Women were included if they were not pregnant or lactating. All subjects signed an informed consent form before inclusion in the study.

\section{Demographic and Clinical Measures}

Anamnesis was performed and age, sex, race, smoking habit, body mass index (BMI), presence of systemic diseases, and use of medications were collected. Race was classified as white or non-white. BMI was measured as the weight $(\mathrm{kg})$ divided by the height squared $\left(\mathrm{m}^{2}\right)$.

The measured clinical periodontal parameters were: percentage of sites that bled on probing (BOP), plaque index (PI), probing depth (PD) and clinical attachment level (CAL). PD and CAL were measured at six sites per tooth (mesio-buccal, buccal, disto-buccal, mesio-lingual, lingual and disto-lingual), except for third molars. A computerized periodontal probe (Probe Florida, Gainesville, FL, USA) was used together with silicon plates $(1.0 \mathrm{~mm})$. Blood pressure was measured using an automatic pressure device (Omron Healthcare, São Paulo, SP, Brazil). Two previously calibrated examiners performed the examinations. Intrarater agreement was 90\% and inter was 70\% for PD and CAL variables, accepting $1 \mathrm{~mm}$ more or less.

\section{Food Frequency Questionnaire}

A food frequency questionnaire (FFO) was applied by a nutritionist in a personal interview. The questionnaire was developed to record the habitual food intake by adults, including questions about 30 items grouped according to the Brazilian standard meal. The items in the FFQ included an extensive list of specific fish and shellfish, as well as walnuts, flaxseed, flaxseed oil, cod liver oil and canola oil. For each item, the categories ranged from never to the number of times each month, each week or each day that were ingested. The purpose of this questionnaire was to eliminate patients who were taking any nutritional supplement or were taking large quantities of $n-3$. From this FFO, it was found that no patient was having supplementation with $\mathrm{n}-3$.

\section{Blood Collection}

Subjects were instructed not to eat for $12 \mathrm{~h}$ prior to blood collection, which was performed at the University Hospital Pedro Ernesto. Blood samples $(20 \mathrm{~mL})$ were taken in the morning ( 8 o'clock) by venous puncture and placed in tubes containing an anticoagulant or not. A total of 4 $\mathrm{mL}$ was transferred to a glass tube (BD Vacutainer, Franklin Lakes, NJ, USA) containing $7.2 \mathrm{mg} \mathrm{K}_{2}$ EDTA for analysis of glycated hemoglobin and blood count. Another $4 \mathrm{~mL}$ were transferred to glass tubes (BD Vacutainer) with 6 $\mathrm{mg}$ of $\mathrm{NaF}$ and $12 \mathrm{mg} \mathrm{Na}{ }_{2}$ EDTA for glucose analysis. A total of $8 \mathrm{~mL}$ was transferred to glass tubes with clot activator to analyze the lipid profile, ultrasensitive C-reactive protein (PCRhs), insulin, PUFAs $n-3$ and n-6 (EPA, DHA, DPA and AA) and adipokines (adiponectin, resistin and leptin). All samples were immediately centrifuged for $5 \mathrm{~min}$, except the $\mathrm{K}_{2}$ EDTA, and used for immediate analysis or stored at $-70^{\circ} \mathrm{C}$ for further analysis. Laboratory tests were also conducted at the University Hospital Pedro Ernesto. Plasma glucose, triglycerides, total cholesterol, high density lipoprotein (HDL-C), lowdensity cholesterol (LDL-C), cholesterol in very low density lipoprotein (VLDL-C), glycated hemoglobin, insulin and leukocyte counts were measured using routine automatic analyzer (DLE, Laboratory Medicine, Rio de Janeiro, RJ, Brazil). PCRhs was determined using a highly sensitive immunoturbidimetric method (DiaSys Diagnostic Systems, 
Holzheim, Germany). PUFAs were analyzed in serum after extraction of lipids, with rust prevented by the addition of butylated hydroxytoluene. The organic phase containing total lipids was dried under nitrogen flow and the residue was methylated (11). Serum fatty acids were extracted and analyzed by gas chromatography. The identification and quantification of peaks in gas chromatography of fatty acid methyl esters were made using a commercial standard (Supelco, Bellefonte, PA, USA).

Adipokine levels were determined using an immunoassay with multiplex bead. Fifty microliters of blood samples were analyzed for adiponectin and resistin using a commercially available (1H-HADK1MAAG) kit, as well as leptin (HADK1MAAG-2K) on a Luminex analyzer (Luminex; MiraiBio, Alameda, CA, USA) according to the manufacturer's instructions. Briefly, 96-well filter were pre-moistened with washing buffer and the solution was aspirated from the wells using a vacuum suction (Millipore Corporation, Billerica, MA, USA). Microspheres coated with monoclonal antibodies against three different analyzed targets were added to the wells. Samples and standards were pipetted into the wells and incubated overnight at $4{ }^{\circ} \mathrm{C}$. The wells were aspirated and washed, and a mixture of secondary biotinylated antibody was added. After incubation for $1 \mathrm{~h}$, streptavidin-conjugated fluorescent protein, R-phycoerythrin (streptavidin-RPE) was added to the beads and incubated for $30 \mathrm{~min}$. After washing to remove non-adherent reagent, buffer solution sheath fluid (Luminex, MiraiBio) was added to the wells with the beads (up to 100 per analysis) to be analyzed in the analyzer microspheres (Luminex $100^{\mathrm{TM}}$; Luminex, MiraiBio). The concentrations of the unknown samples (antigens in blood samples) were calculated from the standard curve using the Bio-Plex Manager Software (Bio-Rad Laboratories, Hercules, CA, USA). The levels of adipokines were expressed as total quantity.

Table 1. Demographic data of patients with periodontitis and gingivitis

\begin{tabular}{lccc}
\hline Variable & Periodontitis & Gingivitis & p-value \\
\hline N. Patients & 15 & 15 & \\
Sex & & & \\
$\quad$ Male & 3 & 3 & $1.00^{*}$ \\
$\quad$ Female & 12 & 12 & \\
Age (mean \pm S.D.) & $45.7( \pm 9.4)$ & $32.1( \pm 7.8)$ & $\leq 0.001^{\#}$ \\
Race & & & \\
White & 7 & 4 & $0.450^{*}$ \\
Non white & 8 & 11 & \\
\hline
\end{tabular}

Note: * Fisher’s Exact Test; ${ }^{*}$ U-test of Mann-Whitney.

\section{Statistical Analysis}

The calculation of sample size was estimated at 15 individuals in each group to have $\alpha=0.05$ and power of 0.80 , considering the mean and standard deviation of the variable DPA (12). Kolmogorov-Smirnov test was performed to assess the normality of the data. Some variables were normal and others not, so nonparametric tests were chosen to use for almost all, with the data being presented as median and interquartile range; except for age, which was presented as mean and standard deviation. Then, to assess the significance of difference between groups, was used Fisher exact test for categorical variables, sex and race and for the other variables was used the Mann-Whitney test, significance was set at 5\% $(p \leq 0.05)$. Analysis of covariance (Ancova) was used to adjust for age. Correlation between fatty acids, adipokines and clinical parameters was performed with Spearman correlation test, and significance was determined at $r \geq 0.5$ and $p \leq 0.01$. Statistical analysis was performed using SPSS v.19.0 (IBM, Chicago, IL, USA).

\section{Results}

\section{Demographic Data}

Demographic data indicated that groups were similar for sex and race. Periodontitis group showed a higher mean age ( $\leq \leq 0.05$ - Table 1). BMI median (interquartile range) in the test group was 28.8 (6.6).

\section{Clinical Data}

Periodontal parameters of both groups are shown in Table 2. The percentages of sites with $\mathrm{PD} \leq 3 \mathrm{~mm}$ and $\mathrm{CAL} \leq 1$ $\mathrm{mm}$ were significantly higher in patients with gingivitis compared to patients with periodontitis $(p \leq 0.01)$. The

Table 2. Median (interquartile range) percentage of periodontal clinical parameters of patients with periodontitis and gingivitis

\begin{tabular}{lccc}
\hline Variable & $\begin{array}{c}\text { Periodontitis } \\
\text { (n: 15) }\end{array}$ & $\begin{array}{c}\text { Gingivitis } \\
\text { (n: 15) }\end{array}$ & p-value * \\
\hline PD (\%) & & & $\leq 0.001$ \\
Shallow $(\leq 3 \mathrm{~mm})$ & $65.0(22.0)$ & $97.6(3.0)$ & \\
Moderate $(4-5 \mathrm{~mm})$ & $21.0(17.0)$ & $2.4(2.5)$ & $\leq 0.001$ \\
Deep ( $\geq 6 \mathrm{~mm})$ & $8.0(17.0)$ & - & - \\
CAL (\%) & & & \\
0-1 mm & $56.0(25.0)$ & $100.0(1.8)$ & $\leq 0.001$ \\
$2-4 \mathrm{~mm}$ & $31.0(12.0)$ & $0(1.8)$ & $\leq 0.001$ \\
$\geq 5 \mathrm{~mm}$ & $10.0(12.0)$ & - & - \\
Pl (\%) & $60.0(33.0)$ & $32.0(34.8)$ & $\leq 0.001$ \\
BOP (\%) & $19.8(24.7)$ & $25.0(33.0)$ & 0.305 \\
\hline
\end{tabular}

Note: *Compared using the $\mathrm{U}$ test of Mann-Whitney. 
percentage of sites with CAL 2-4 $\mathrm{mm}$ was significantly higher in patients with periodontitis compared to patients with gingivitis $(p \leq 0.01)$. The percentage of positive sites for dental plaque was significantly higher in patients with periodontitis $(p \leq 0.01)$. However, there was no difference in the percentage of BOP between groups ( $p>0.05)$.

\section{PUFAs and Adipokines}

There was no significant difference between the groups for resistin, adiponectin and leptin ( $p>0.05)$. However,

there was a tendency for lower values of adiponectin in periodontitis patients, even after Ancova correction. Regarding DHA, DPA, EPA and AA, difference was significantly larger for the group of periodontitis patients compared to gingivitis group $(p=0.029, p=0.004, p=0.16$ and $p=0.002$, respectively) (Table 3 ).

The ratios between resistin and fatty acids were significantly higher in gingivitis group (res/EPA $p=0.006$; res/ DHA $p=0.002$; res/AA $p=0.001$; res/DPA $p=0.001$ ); as well as the ratios between adiponectin and fatty acids (adipon/EPA $\mathrm{p}=0.004 ;$ adipon/DHA $\mathrm{p}=0.017$; adipon $/ \mathrm{AA}$ $p=0.007$; adipon/DPA $p=0.003$ ). The ratios between leptin and fatty acids showed no statistically significant difference (Table 4).

$(\mu \mathrm{mol} / \mathrm{L})$ and adipokines $(\mathrm{ng} / \mathrm{mL})$ of patients with periodontitis and gingivitis

\begin{tabular}{|c|c|c|c|c|c|}
\hline Variables & $\begin{array}{l}\text { Periodontitis } \\
\text { (n: 15) }\end{array}$ & Gingivitis (n: 15) & p-value* & Ancova** & Power \\
\hline Resistin & $5.7(4.4)$ & $6.3(4.8)$ & 0.093 & 0.184 & $43 \%$ \\
\hline Adiponectin & $9613.8(13405.1)$ & 19001.6 (11091.7) & 0.089 & 0.087 & $25 \%$ \\
\hline Leptin & $21.5(32.3)$ & $10.5(25.3)$ & 0.174 & 0.475 & $31 \%$ \\
\hline DHA (C22:6w3) & 213.1 (124.9) & $165.0(90.7)$ & 0.029 & 0.061 & $85 \%$ \\
\hline DPA (C22:5W3) & $54.8(35.0)$ & $34.5(25.8)$ & 0.004 & 0.048 & $90 \%$ \\
\hline EPA (C20:5W3) & $51.2(25.4)$ & $27.1(31.4)$ & 0.016 & 0.532 & $46 \%$ \\
\hline AA (C20:4W6) & $1045.4(522.9)$ & $561.0(544.1)$ & 0.002 & 0.009 & $90 \%$ \\
\hline
\end{tabular}

Table 4. Median (interquartile range) of the ratio of adipokines $(\mathrm{ng} / \mathrm{mL})$ and polyunsaturated fatty acids $(\mu \mathrm{mol} / \mathrm{L})$ in patients with periodontitis and gingivitis

\begin{tabular}{lccccc}
\hline Variables & $\begin{array}{c}\text { Periodontitis } \\
(\mathrm{n}: 15)\end{array}$ & Gingivitis (n:15) & p-value* & Ancova** & Power \\
\hline Res/EPA & $0.12(0.11)$ & $0.39(0.34)$ & 0.006 & 0.096 & $76 \%$ \\
Res/DHA & $0.03(0.02)$ & $0.05(0.05)$ & 0.002 & 0.018 & $>90 \%$ \\
Res/AA & $0.006(0.01)$ & $0.015(0.01)$ & 0.001 & 0.003 & $>90 \%$ \\
Res/DPA & $0.10(0.09)$ & $0.25(0.31)$ & 0.001 & 0.053 & $84 \%$ \\
Adipon/EPA & $228.29(424.67)$ & $564.70(855.88)$ & 0.004 & 0.066 & $86 \%$ \\
Adipon/DHA & $50.06(99.28)$ & $123.76(105.16)$ & 0.017 & 0.034 & $73 \%$ \\
Adipon/AA & $10.61(20.22)$ & $31.98(43.51)$ & 0.007 & 0.015 & $70 \%$ \\
Adipon/DPA & $204.38(182.05)$ & $690.19(759.45)$ & 0.003 & 0.016 & $90 \%$ \\
Lep/EPA & $0.43(0.70)$ & $0.35(0.35)$ & 0.852 & 0.856 & $6 \%$ \\
Lep/DHA & $0.09(0.13)$ & $0.08(0.11)$ & 0.852 & 0.697 & $14 \%$ \\
Lep/AA & $0.02(0.03)$ & $0.02(0.02)$ & 0.950 & 0.634 & $5.5 \%$ \\
Lep/DPA & $0.44(0.50)$ & $0.44(0.38)$ & 0.756 & 0.622 & $5 \%$ \\
\hline
\end{tabular}

Docosahexaenoic acid (DHA); docosapentaenoic acid (DPA); eicosapentaenoic acid (EPA); arachidonic acid (AA); resistin (Res); adiponectin (Adipon); leptin (Lep). Note: *Compared using the $\mathrm{U}$ test of Mann-Whitney; **Data were compared using Ancova, adjusting for differences in age between the groups.

\section{Blood Parameters}

Levels of triglycerides and glucose were higher in periodontitis patients ( $p=0.050$ and $p=0.019$ ), while HDL levels were lower in patients with periodontitis $(p=0.050)$. For all other evaluated parameters, there was no significant difference between groups.

\section{Correlations}

Correlations between PUFAs, adipokines and clinical parameters are shown in Table 5. PD had a positive correlation with DHA ( $r=0.5, p=0.007)$, DPA $(r=0.6, p=0.001)$ and AA $(r=0.6$; $p=0.001)$. CAL had a positive correlation with DHA $(r=0.5, p=0.010)$, DPA $(r=0.5, p=0.003)$ and AA ( $r=0.6, p=0.001)$. PI had a positive correlation with DPA $(r=0.5, p=0.008)$. BOP did not show significant correlations. Correlations between PUFAs and adipokines and among themselves are shown in Table 6. None of the correlations was statistically significant.

\section{Data Adjusted for Age (Ancova)}

After adjusting for age, differences remained significantly higher for DPA and AA ( $p=0.048$ and $p=0.009$, respectively) for the periodontitis group (Table 3 ). The medians of the ratios between adipokines and fatty acids remained significantly higher for res/ DHA and res/AA ( $p=0.018$ and $p=0.003$, respectively); for adipon/DHA, adipon/AA and adipon/DPA ( $p=0.034, p=0.015$ and $p=0.016$, respectively) for the gingivitis 
group (Table 4). In blood parameters, differences were no longer significant for triglyceride, HDL and glucose and became significantly higher for insulin in periodontitis group ( $p \leq 0.001)$.

\section{Discussion}

In the present study, all fatty acids showed higher levels in periodontitis group, with significant difference for DPA and AA. In a previous study by the same group, Figueredo et al. (12) also found higher levels in periodontitis group, with significance for all fatty acids. Ramirez-Tortosa et al. (13) found higher levels of AA in patients with periodontitis. These results suggest that higher AA levels are implicated in pathogenesis of periodontitis. Regarding DHA, Ramirez-Tortosa et al. (13) found no significant difference when comparing patients with periodontitis and control. Requirand et al. (14) found lower levels in patients with bone loss. Such differences are difficult to explain, but may be related to intake of $n-3$. In the present study, the food frequency questionnaire was made in order to eliminate patients who used any type of supplementation

Table 5. Correlation between DHA, EPA, DPA, AA and adipokines and clinical parameters

\begin{tabular}{lcccccccc}
\hline Variables & & DHA & DPA & EPA & AA & Adiponectin & Leptin & Resistin \\
\hline PD (mm) & $\mathrm{r}$ & 0.5 & 0.6 & 0.4 & 0.6 & -0.1 & 0.2 & -0.3 \\
& $\mathrm{p}$ & 0.007 & 0.001 & 0.019 & 0.001 & 0.428 & 0.188 & 0.067 \\
& $\mathrm{r}$ & 0.5 & 0.5 & 0.3 & 0.6 & -0.2 & 0.3 & -0.3 \\
CAL (mm) & $\mathrm{p}$ & 0.010 & 0.003 & 0.080 & 0.001 & 0.197 & 0.139 & 0.103 \\
& $\mathrm{r}$ & 0.2 & 0.5 & 0.0 & 0.4 & -0.4 & -0.1 & -0.2 \\
Pl (\%) & $\mathrm{p}$ & 0.200 & 0.008 & 0.787 & 0.045 & 0.054 & 0.463 & 0.360 \\
& $\mathrm{r}$ & -0.0 & 0.1 & -0.2 & -0.0 & -0.1 & -0.2 & 0.1 \\
BOP (\%) & $\mathrm{p}$ & 0.778 & 0.607 & 0.260 & 0.961 & 0.423 & 0.209 & 0.771 \\
\hline
\end{tabular}

Docosahexaenoic acid (DHA); docosapentaenoic acid (DPA); eicosapentaenoic acid (EPA); arachidonic acid (AA); probing depth (PD); clinical attachment level (CAL); plaque index (PI); bleeding on probing (BOP). Note: *Correlation using the Spearman correlation test.

Table 6. Correlation between DHA, DPA, EPA, AA and adipokines and between adipokines

\begin{tabular}{lcccccccc}
\hline Variables & & DHA & DPA & EPA & AA & Adiponectin & Leptin & Resistin \\
\hline \multirow{2}{*}{ Adiponectin } & $\mathrm{r}$ & -0.196 & -0.161 & 0.220 & -0.222 & - & -0.150 & -0.079 \\
& $\mathrm{p}$ & 0.299 & 0.394 & 0.243 & 0.238 & - & 0.429 & 0.677 \\
& $\mathrm{r}$ & 0.225 & 0.069 & 0.289 & 0.227 & -0.150 & - & 0.051 \\
\multirow{2}{*}{ Leptin } & $\mathrm{p}$ & 0.232 & 0.717 & 0.121 & 0.227 & 0.429 & - & 0.788 \\
& $\mathrm{r}$ & 0.027 & -0.190 & -0.190 & 0.026 & -0.079 & 0.051 & - \\
\multirow{2}{*}{ Resistin } & $\mathrm{p}$ & 0.887 & 0.315 & 0.313 & 0.892 & 0.677 & 0.788 & - \\
& & & & & & & \\
\end{tabular}

Docosahexaenoic acid (DHA); docosapentaenoic acid (DPA); eicosapentaenoic acid (EPA); arachidonic acid (AA). Note: ${ }^{*}$ Correlation using the Spearman correlation test. or who ingested large amounts of $n-3$, and the obtained values are below those recommended by the World Health Organization (15); even so, differences between groups may have remained.

Serum adipokine levels between groups of patients with gingivitis and with periodontitis showed no significant difference. Furugen et al. (16) and Saito et al. (6) also found no significant difference to adiponectin, with lower values in the periodontitis group. A possible limitation in these studies may be the composition of the groups.; Saito et al. (6) only included women, smokers and non-smokers, Furugen et al. (16) only included Japanese of both sexes, smokers and non-smokers; and the degree of involvement of periodontitis (extension and severity), as Saito et al. (6) include moderate to severe periodontitis, while Furugen et al. (16) classified periodontitis as the presence of at least one pocket $\geq 6 \mathrm{~mm}$. In the present study probably if the number of patients were increased, there could be statistical difference, since a tendency to lower values of resistin and adiponectin in the group with periodontitis was observed.

Regarding resistin, Devanoorkar et al. (7) and Furugen et al. (16) also found no significant differences, but their levels were increased in the periodontitis group. On the other hand, Saito et al. (6) found significant differences with increased levels in the periodontitis group. There were differences in the compositions of the groups, as already mentioned, between this study and those of Furugen et al. (16) and Saito et al. (6), while Devanoorkar et al. (7) included patients of both sexes and excluded smokers. BMI $\geq 25 \mathrm{~kg} / \mathrm{m}^{2}$ was included in the samples of Furugen et al. (16) and Saito et al. (6), but excluded from the Devanoorkar et al. (7) study. There were also differences in the degree of involvement and classification of periodontitis among studies. A limitation of the present study was that the body weight was not standardized in control group patients, which rules out the calculation of BMI. This did not allow to completely control the BMI effects on the results and thus, it might be a source of bias. Overweight and obesity may alter adipokines and fatty acids levels, due to increased inflammatory status.

Leptin showed higher levels in periodontitis group, but did not reach statistical significance. Karthikeyan and Pradeep (17) and Shimada et al. (18) found significant differences in leptin levels, higher among subjects 
with periodontitis compared with those considered healthy, which is similar to the results of this study. Ay et al. (4) found no difference in serum levels between groups of patients who were divided into healthy, gingivitis, chronic and aggressive periodontitis. A possible explanation for this discrepancy in results is the involvement of factors that may have influenced the values of leptin, such as BMI. Karthikeyan and Pradeep (17) and Shimada et al. (18) used the normal range of $\mathrm{BMI}$ as a selection criterion. In addition to other factors, such as the inclusion of smokers, the degree of inflammation found in patients and classification of periodontitis, Ay et al. (4) included aggressive periodontitis; the other authors included only chronic periodontitis.

There was no correlation in this study between levels of adipokines and periodontal parameters (PD, CAL, PI and BOP). On the other hand, Shimada et al. (18) found a positive correlation between leptin levels and the following clinical parameters: $\mathrm{PD}, \mathrm{CAL}$, bone loss and $\mathrm{BMI}$, which sustain the inflammatory role of this adipokine. Furugen et al. (16) found a positive correlation between BOP and resistin, which indicates its presence in inflammation. They found a significant but weak negative correlation between adiponectin levels and $\mathrm{CAL}$; this result the authors credited $\vec{s}$ to the low levels of adiponectin observed in males with severe clinical attachment loss. Adiponectin also correlated negatively with leukocyte count, which indicates its role as an anti-inflammatory mediator.

It may be concluded that generalized chronic periodontitis presents significantly greater differences in levels of fatty acids when compared to gingivitis. Adiponectin showed a tendency to lower values in periodontitis group, even after Ancova correction. The results of the ratios suggested a lesser proportion of adiponectin and resistin in relation to the fatty acids in periodontitis.

\section{Resumo}

As adipocinas estão presentes em processos inflamatórios e podem estar diretamente relacionadas à doença periodontal. Além disso, suas atividades podem ser reguladas pelos ácidos graxos. Este estudo teve como objetivo quantificar as concentrações das principais adipocinas, leptina, adiponectina e resistina, e dos ácidos graxos: ácido docosahexaenóico (DHA), ácido docosapentaenóico (DPA), ácido eicosapentaenóico (EPA) e ácido araquidônico (AA), em pacientes com periodontite crônica generalizada. Como objetivo secundário, avaliar as proporções destas substâncias no sangue desses pacientes. 0 estudo incluiu 15 pacientes sistemicamente saudáveis com periodontite crônica generalizada (grupo teste) e 15 com gengivite (grupo controle). Foram coletados parâmetros médicos e periodontais e amostras de sangue. As concentrações séricas dos ácidos graxos foram analisadas por cromatografia gasosa e as das adipocinas foram analisadas pelo método multiensaio multiplex. Não houve diferença significativa entre os niveis de adipocinas entre os grupos. No entanto, houve uma tendência para menores valores nos níveis da adiponectina nos pacientes com periodontite. Com relação aos ácidos graxos, os valores foram significativamente maiores no grupo teste em comparação com os controles. As razões entre res/DHA, res/AA, adipon/DHA, adipon/AA e adipon/DPA foram significativamente menores no grupo teste. Não houve correlação significativa entre as adipocinas e os parâmetros clinicos e entre os níveis de adipocinas e ácidos graxos. Conclui-se que pacientes com periodontite crônica generalizada apresentaram níveis significativamente maiores de ácidos graxos em relação à gengivite, adiponectina apresentou uma tendência a valores menores no grupo periodontite, mesmo após a correção de Ancova. Os resultados das razões sugerem uma menor proporção de adiponectina e resistina em relação aos ácidos graxos em pacientes com periodontite crônica generalizada.

\section{References}

1. Armitage GC. Periodontal diagnoses and classification of periodontal diseases. Periodontol 2000 2004;34:9-21.

2. Silva TA, Garlet GP, Fukada SY, Silva JS, Cunha FQ. Chemokines in oral inflammatory diseases: apical periodontitis and periodontal disease. J Dent Res 2007;86:306-319.

3. Yamamoto M, Fujihashi $K$, Hiroi T, McGhee JR, Van Dyke TE, Kiyono H. Molecular and cellular mechanisms for periodontal diseases: role of Th1 and Th2 type cytokines in induction of mucosal inflammation. J Periodontal Res 1997;32:115-119.

4. Ay ZY, Kirzioglu FY, Tonguc MO, Sutcu R, Kapucuoglu N. The gingiva contains leptin and leptin receptor in health and disease. Odontology 2012;100(2):222-231.

5. Otero M, Lago R, Lago F, Casanueva FF, Dieguez C, Gomez-Reino JJ, et al.. Leptin, from fat to inflammation: old questions and new insights. FEBS lett 2005;579:295-301.

6. Saito T, Yamaguchi N, Shimazaki Y, Hayashida H, Yonemoto K, Doi $Y$, et al.. Serum levels of resistin and adiponectin in women with periodontitis: the Hisayama study. J Dent Res 2008;87:319-322.

7. Devanoorkar A, Dwarakanath CD, Gundanavar G, Kathariya R, Patil SR. Evaluation of serum resistin levels in periodontal health and disease and effects of non surgical periodontal therapy on its levels. Dis Markers 2012;32:289-294.

8. Calder PC. N-3 polyunsaturated fatty acids and inflammation: from molecular biology to the clinic. Lipids 2003;38:343-352.

9. Drevon CA. Fatty acids and expression of adipokines. Biochim Biophys Acta 2005;1740:287-292.

10. Armitage GC. Development of a classification system for periodontal diseases and conditions. Ann Periodontol 1999;4:1-6.

11. Bhattacharya A, Lawrence RA, Krishnan A, Zaman K, Sun D, Fernandes G. Effect of dietary n-3 and n-6 oils with and without food restriction on activity of antioxidant enzymes and lipid peroxidation in livers of cyclophosphamide treated autoimmune-prone NZB/W female mice. J Am Coll Nutr 2003;22:388-399.

12. Figueredo CM, Martinez GL, Koury JC, Fischer RG, Gustafsson A. Serum levels of long-chain polyunsaturated fatty acids in patients with periodontal disease. J Periodontol 2013;84:675-682.

13. Ramirez-Tortosa MC, Quiles JL, Battino M, Granados S, Morillo JM, Bompadre $\mathrm{S}$, et al.. Periodontitis is associated with altered plasma fatty acids and cardiovascular risk markers. Nutr Metab Cardiovasc Dis 2010;20:133-139.

14. Requirand $P$, Gibert $P$, Tramini $P$, Cristol JP, Descomps B. Serum fatty acid imbalance in bone loss: example with periodontal disease. Clin Nutr 2000;19:271-276.

15. WHO and FAO joint consultation: fats and oils in human nutrition. Nutr Rev 1995;53:202-205.

16. Furugen $R$, Hayashida $H$, Yamaguchi $N$, Yoshihara A, Ogawa H, Miyazaki $H$, et al.. The relationship between periodontal condition and serum levels of resistin and adiponectin in elderly Japanese. J Periodontal Res 2008;43:556-562.

17. Karthikeyan BV, Pradeep AR. Gingival crevicular fluid and serum leptin: their relationship to periodontal health and disease. J Clin Periodontol 2007;34:467-472.

18. Shimada Y, Komatsu Y, Ikezawa-Suzuki I, Tai H, Sugita N, Yoshie H. The effect of periodontal treatment on serum leptin, interleukin-6, and C-reactive protein. J Periodontol 2010;81:1118-1123. 